\title{
Instructional Communication Between Teachers and Children With Different Abilities in the Inclusion School
}

\author{
Mutiah* \\ Communication Science Department, \\ Faculty of Social Sciences and Law \\ Universitas Negeri Surabaya \\ Surabaya, Indonesia \\ Mutiah@unesa.ac.id
}

\author{
Diyah Utami \\ Department of Sociology, \\ Faculty of Social Sciences and Law \\ Universitas Negeri Surabaya \\ Surabaya, Indonesia \\ diyahutami@unesa.ac.id
}

\begin{abstract}
Children with different abilities have limited senses, but as human beings they have the same need to communicate. Government policy requires some state schools to provide quotas for children with different abilities. Government policy encourages schools to prepare all facilities and skilled teaching staff to handle children with different abilities. The style or way of communicating children with different abilities is not always understood by everyone, only a few have these skills so that communication becomes the main tool for all who are in the school environment to interact with children with different abilities. Instructional communication can be applied by teachers and students when interacting at school, because this communication invites communication participants to understand all verbal and non verbal messages face to face interaction, in line with the theory of SMCR. This research was conducted at Mumtaz Sidoarjo school, in this school has 12 inclusion children with 4 types of ADHD students, 1 Down Syndrome, 6 students with dyslexia and 1 child with dyscalculia. Using a qualitative approach to the case study data collection method, which is digging data through interviews, observations and documents such as school internal magazines for analysis. Then this research will look comprehensively the transactional communication process that occurs between teachers and inclusive children at SD Mumtaz Sidoarjo, East Java
\end{abstract}

Keywords: Inclusion, communication, instructional

\section{INTRODUCTION}

Inclusion or different abilities is a term that is placed for children who have distinctive characteristics compared to normal children in general. Inclusive children are characterized by an inability to manage emotional, mental and physical limitations. Some types of children with different abilities are visually impaired, deaf, down syndrome. Nevertheless the inclusive child has the same right as a citizen to receive education, as stated in the 1945 Constitution Article 31 paragraph (1) which states that "every citizen has the right to education". Inclusive education is an educational service that includes children with different abilities, learning with normal children of their age in the regular class. Usually the public knows that the education of children with different abilities in special schools is not so, even now in 2014 many public schools have implemented government policies to accept children with different abilities as their students. Conceptually and paradigmatically, inclusive education according to Farel has an accommodating character, by accepting each student and avoiding negative labeling, and in its operations actively involving related parties [1]. The existence of government policies regarding the education of children with different abilities attending public schools, inevitably requires effective communication skills, the most reliable communication is verbal communication accompanied by nonverbal cues, for example for children with autism.Language impairment has a severe impact on the level of functioning in children with autism spectrum disorder (ASD) [2]. Likewise for example for children with Down Syndrome (DS) they have different ways of communicating, DS is used a greater number of appropriate terms to refer to the object of attention [3]. Oral communication has important elements, namely sources, channels, messages, codes (signs or symbols) and terms of reference [4]. Verbal communication is man's most effective method of making his thoughts known to other people and organizing his own conceptual thinking [5] in the learning process and environmental adaptation for children with different abilities, because if not accompanied by a warm atmosphere and communication inclusion children will experience anxiety, and this anxiety will affect to adulthood and when in social situations can affect the way they speak, it causes social anxiety, social anxiety in adults who stutter leads to greater emotional 
challenges, less satisfaction with speech, and increased avoidance of speaking situations [6] therefore there must be a role for good communication management between teachers and the school environment to reduce the anxiety and uncertainty felt when inclusion learners adjust and can adapt in the school environment [7]. One of the schools that accepts students with different abilities is SD Mumtaz Sidoarjo. SD Mumtaz started the program to accept inclusive children since 2017, this program is the application of government policy. The school categorizes children with different abilities by conducting several psychological tests, assessments and observations. This is done because some parents when registering school for their children with different abilities, they do not know what kind of child is special needs. Each type of different abilities has a different way of handling, that's why psychological testing and checking to experts related to the type of different abilities is very important. SD Mumtaz currently has 12 children with different abilities, with 4 types of ADHD students, 1 Down Syndrome, 6 students with dyslexia and 1 child with dyscalculia. On a daily basis, children with different abilities interact a lot with other friends who are generally normal. Basically, the concern is how to communicate with inclusive children in public school environments, the difference in interpreting certain objects is sometimes a problem that is often encountered. Therefore communication becomes an important factor that is able to bridge between inclusion students and teachers. The world of education requires a comprehensive and systematic understanding of the use of communication in the learning process. Educational communication will show the direction of the process of social construction of the reality of education. Communication is controlled and conditioned for educational purposes. Educational communication is a process and communication activity specifically designed for the purpose of increasing added value for the target parties, or increasing literacy in many fields. One of the educational communication that is often used is instructional. Instructional communication is defined as a communication study consisting of various variables such as strategy, process, technology, and /or a system related to formal teaching and mastery of the material and modification of learning outcomes [8]. Communication is not only interpreted as a verbal message exchange but more than that there is an instructional process in an ongoing communication. Instructional presents many symbols that can be interpreted as various things. In the five-sense instructional communication as the most widely used channel, and essentially in the process of communication takes place, communication tends to be dynamic and there is a rapid change in communication participants, because in the context of instructional communication all communication participants can be both a communicator and can be as a communicant, the communication process took place simultaneously by interpreting all messages both verbal and non verbal. Instructional communication is more focused on its function as a means to an end, and not in a broader and complex sense that covers all aspects of human life [9]. This communication process can be explained in the SMCR model developed by Berlo. According to Berlo all communication participants also react to the behavior that occurs in the communication activities. This communication model is commonly referred to as the Berlo communication model, which focuses on the communication process and emphasizes the meaning of communication in humans so that the interpretation of a message depends on the meaning of the words or gestures of communicators and communicants [10]. According to the SMCR model the quality of communication between the source and recipient of the message is influenced by the factors of communication skills, attitudes, knowledge, social systems, and culture of the two defending parties [11].

\section{METHOD}

This research uses a qualitative approach, qualitative research presents data holistically and deeply [12]. with the case study method, in the case study method, the data is extracted by interviewing the research subject in this case the teacher and student with different abilities and observation, the writer will directly observe the communication process that takes place between the teacher and students in the class, therefore the author's presence becomes absolute as an instrument of this research, understanding the situational dimension also involves going beyond observable actions and utterances [13]. In this study, the subject of the study was grade 1 teachers and inclusive students in grade 1. At Mumtaz Elementary School, there were 6 classes for the first grade and each class had one inclusive student. Data Analysis Techniques: Information or data that has been collected will be grouped according to categories with the purpose of the research and the research problem being sought. It is very possible for researchers to interpret the data or information using a number of schemes. According to Marshall and Rossman [12] data collection and analysis must be a concurrent process. Furthermore, the results of this information or data are formatted in the form of narratives or images in accordance with the procedures of analysis techniques in qualitative research approaches. The data of this research will be presented in narrative form in the form of a script or picture and also an explanation of educational communication models found during observation. In ensuring internal validity, qualitative approach strategies can be used as needed. In this study two steps will be used namely;

1. Triangulation of data, data will be collected through multiple sources to include interviews, observations and analysis ofdocuments

2. members' examination, informants will act as examiners throughout the analysis process. Continuous dialogue regarding the interpretation of the reality and meaning of the informants will ensure the honesty of data 


\section{RESULTS AND DISCUSSION}

This study looks at the practices and teaching processes of regular teachers in the Mumtaz Elementary School in Sidoarjo Regency. Researchers only see children with different abilities in grade 1 only. At Mumtaz Elementary School, there are six rooms for first grade, named class 1.A to 1.F. almost all classes have different abilities students, there are 7 children with different abilities in class 1 . The informants of this study are Shawdo and accompanying teachers, but only 3 people can interview researchers and observe the teaching process in January 2020, following a table of informants whose names are researchers disguise using initials.

Table.3.1 Research Informant Data

\begin{tabular}{|l|l|l|}
\hline No & Name & Age \\
\hline 1 & R & 35 years old \\
\hline 2. & A & 32 years old \\
\hline 3 & N & 38 years old \\
\hline
\end{tabular}

In general MUMTAZ schools have several regular teachers who are equipped with the ability to teach children with different abilities, but school management still provides special teachers or shadow for guardians of students who want their children accompanied by Shawdo. This is in accordance with what R's research informants admit, as follows

"every child with different abilities is accompanied by Shawdo (special teacher), and the class accompanying sister, indeed not all because it is related to additional costs but the teacher here already has the basic ability to teach children with needs special. "

While in the teaching and learning process, the teacher applies an approach to teach children with different abilities that have been recommended by experts, namely by being kind and positive, using appropriate and attractive classroom settings, speaking clearly and facing students, using appropriate strategies or modifications learning, using effective learning media (so that students do not tantrum), as well as cooperation between the inclusion coordinator, homeroom teacher, parents, children with different abilities, subject teachers and shadow teachers (special supervisors). As stated by A as follows:

"If children with different abilities learn gradually. If they were tantrums, we would take them to the playroom. Still learning there but while playing "

All devices in inclusive schools have a role in educational services for inclusive children, one of which is the provision of energy to treat inclusive children, and the provision of learning resource space as a place for channeling emotions when children with different abilities are experiencing high energy turmoil. As for what Mumtaz Elementary School teachers do in providing educational services, that is by training the courage, balance, and coordination of children's motor maturity. These inclusion children are also given gross motor training, such as walking on a long board without holding on. Teachers also provide exercises and guidance so that children with different abilities can control themselves and socially, as revealed by informants $\mathrm{N}$

"all of these inclusive school devices, are responsible and have a role in services for children with different abilities"

The method of self and social control is done by teachers with games and involving several other fellow children with different abilities themselves. For example by playing ball, then the ball is thrown at the participant. The aim of this game is to instill a sense of social, sharing and responsibility. In addition to instilling a sense of responsibility and social, children with different abilities are also trained to focus and concentrate. For example in ADHD children to solve problems, the media used are toys. When an ADHD child is playing, the teacher keeps watching and directing the child to focus and be able to finish the game. ADHD children have high intelligence but emotional levels are out of control, according to research informant A, ADHD children teach children easier, communicating even more smoothly.

"Children with different abilities ADHD type more quickly accept lessons and new messages than other types of ABK"

The interesting side of this ADHD child is also the voter, this child will not want to obey other teachers or others at school, other than one person who has already comfortable for him. Children with ADHD have their own attitudes, tend not to be set. This was confirmed by informant A as follows

"ADHD children if they already know and are close to one teacher he does not want to with other teachers, as well as with friends. This ADHD child can not be ruled he is also difficult to manage. For example, given the task of memorizing, he does not want to even though he has memorized it."

The communication process of children with different abilities is related to the subject matter. All messages given by the accompanying teacher and shadow were aimed at making children with different abilities able to show changes in cognitive, affective and behavior. For example when this child is tantrum, emotional, does not want to do anything then shadow will make a personal communication approach. Of course, each companion has a different way, and is required to innovate in communication because the emotional reactions of children with 
diffrent abilities often change, for example, as told by informant A

"Usually when children with different abilities has tantrums, I will whisper to him, megajak he plays or food she likes. All of that goes back to the skills of each teacher, I always look for communication approach innovations because every day the problem is definitely different"

All the companions of children with different abilities at SD Mumtaz are indeed diverse, only 3 people who become research informants who have qualified knowledge background to address and treat children with different abilities skillfully. Among them are graduating in Psychology, Special Education graduates, and Counseling Guidance graduates. Research informant $\mathrm{N}$ is the only teacher with a background in Special Education, $\mathrm{N}$ has initiated many educational programs for children with different abilities at SD Mumtaz. One of them is a mentoring program for dyslexic children who are still having difficulty reading or recognizing letters, this program can also be categorized as therapy. This therapy can use a variety of media, one of which is image media. As stated $\mathrm{N}$ follows

"dyslexia therapy with JARI (Clear, Appreciation, Light and Intensive) techniques to motivate dyslexic children in understanding letters, its nature of assistance in the learning resource room. the introduction of letters using images"

Facilities that have been provided by the school are used as much as possible but the school and educators realize that this is not enough, because the most important thing that needs to be applied to teachers is the ability to communicate dyadic or open and familiar dialogue with inclusive students. This communication ability requires innovation considering that children with different abilities have rapid emotional changes, each teacher has his own approach. Like the research informant $\mathrm{A}$, it was quite successful in changing their students from being unable to read now to being able to read

"before I was accompanied, my student did not want to write and could not read, after I accompanied him he wanted to write and read. I use my own method to approach it. With a toy that he likes I bring to class, or accompany him when I want to leave the classroom. Because children with different abilities, if they like one teacher, they don't want others. Moreover, my guidance child is autistic, more silent."

According to the informant, the most important thing is the communication of the children with different abilities assistant teacher with the students' parents. So that the atmosphere of learning at school and when at home can be the same. Children with different abilities have less focus power, if parents teach is not the same as how to learn at school, children with different abilities will be confused and return tantrums then difficult to manage. Basically, communication activities carried out by child companion teachers with different abilities rely on the five senses. Focused eye contact, gentle sounds of positive and consistent words, and expressions of appreciation make these children with different abilities touched their hearts, even they may be more obedient to the companion than to the homeroom teacher.

Picture. 1. SMCR Communication Model

\section{Berlos's SMCR Model of communication}

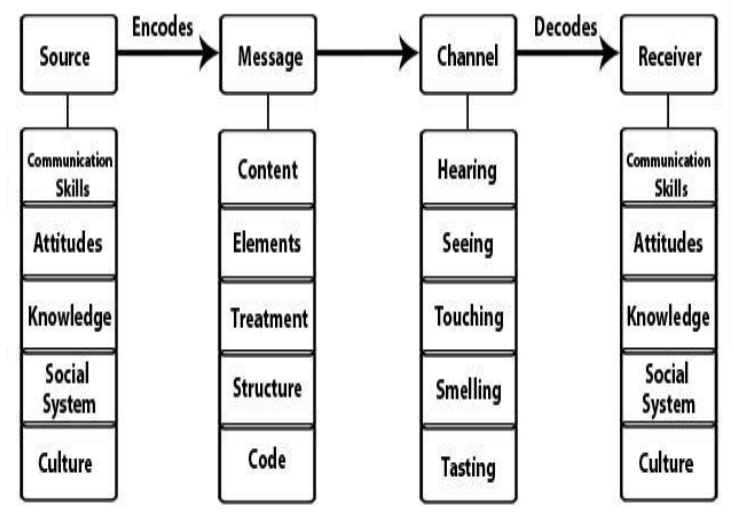

Source: Mulyana, 2007

Referring to Berlo SMCR communication model stands for Source (S) Message (M), Channel (C) and Receicer (R), this SMCR model if adapted in the learning process [14], advantages Berlo's model, this model is not limited to public communication or mass communication, but also interpersonal communication and various forms of written communication [15], it can be analyzed the conditions of teaching conducted by teachers in inclusive schools. As follows, the first aspect of the source or source of the sender of the message in this study are the accompanying teachers who have communication skills, a positive attitude, equipped with knowledge about children with different abilities. This of course is fulfilled because they come from backgrounds according to what the school needs to guide children with different abilities. While the social system and culture aspects are not very influential, because children with different abilities are more easily invited to communicate effectively if all the behaviors and directives of their supervisors feel sincerely. Then in the aspect of the message, teachers and children with different abilities communicate more with subject matter and use a lot of codes either the five senses or other media such as pictures and toys. The channel of the communication process of teachers and children with different abilities is the five senses themselves, all five senses are very reliable to convey messages of lessons for children with different abilities. Starting from seeing, teachers must maintain 
eye contact, teachers and children with different abilities exchange messages, but teachers must listen more and the five senses most prominent according to data from interviews with informants are sincere feelings and must be sensitive, because children with different abilities this cannot clearly show what they want or don't want. The final element is the recipient, if you see the theory of course children with different abilities lack good communication skills, but they can respond with expressions, such as shouting, angry, sad or silent. Children with different abilities will also be positive if the source of the sender of the message is someone he knows closely. Of course the recipient element of the Berlo model is slightly different when it is a child with different abilities.

\section{CONCLUSION}

There are four basic elements of instructional communication teachers and students with disabilities in elementary school Mumtaz, namely:

1. Source; The teacher must be a person with special skills and educational background for children with different abilities, psychology or at least counseling guidance. Because they have good communication techniques with students with different abilities that they accompany.

2. Message; messages delivered to children with different abilities, must be simple, focused, can use attractive visuals such as pictures and interesting objects and carried out repeatedly

3. Channel; are all sense organs, even sincere feelings can be good channels. Because children with different abilities choose who they will communicate with.

4. Reciver; the recipient of the message is a child with different abilities with all its special characteristics, therefore it must be understood that the purpose of communication is not always the same between the sender and the recipient of

\section{REFERENCES}

[1] SA Sholawati, "Manajemen Pembelajaran Pendidikan Inklusi Pada Anak Berkebutuhan Khusus di SD $N$ Kalirungkut-1 Surabaya," ABDAU, vol. 2, no. 1, p. 40, 2019.

[2] Green HL, "No Evaluation of Mismatch Negativity as a Biomarker for Language Impairment in Autism Spectrum Disorder," TitlesJ. Commun. Disord., vol. 84, no. 3, p. 3, 2020.

[3] P. Migue Igaleotea, Elena Checaa, "Joint attention and vocabulary development in toddlers with Down syndrome and their peers with typical development: The role of maternal interactive style," J. Commun. Disord., vol. 84, no. 84 , p. $1,2020$.
[4] A. Liliweri, Verbal and Non Verbal Communication. PT Citra Aditya Bakti, 1994.

[5] CW Bending, communication and the schools. https://doi.org/10.1016/C2013-0-05569-7, 1970.

[6] id Wardf Hilda Sonsterudab, Kristin Billaud, "What do people search for in stuttering therapy: Personal goalsetting as a gold standard ?, " J. Commun. Disord., vol. 82, p. 1, 2019.

[7] AP Susilo, "Understanding Communication for the Adaptation of Children with Deaf Children in Inclusive Schools," Interak. Communication Studies., vol. 6, no. 2, pp. 1-10, 2017.

[8] S. Nuryani, 1, P. Hadisiwi, 2, Dan, and K. El Karimah, "Teacher Communication Patterns for Students with Different abilities in Schools Preventing Vocational Inclusion," J. Kaji. Commune., vol. 4, no. 2, p. 3, 2016.

[9] DP Maladzan and MS Drajat, "Instructional Communication Patterns in Inclusive Schools (Case Study of Active Learning Learning Methods for Children with Different abilities of Kindergarten Classes at Gema La Roche School in Jakarta)," in Proceedings of Public Relations, 2015 , p. 1.

[10] T. Haryadi, "Adaptation of the Theory of DiffusionInnovation in the 'Yuk Benahi' Game With the SMCR Communication Approach," J. Audience, vol. 1, no. 1, p. 5, 2018.

[11] S. Mutmainah, "The Management of Cigarette Company Impression: A Study of Sampoerna Reporting on Websites Using Berlo's SMCR Model," Accounts. Multiparadigm, vol. 2, no. 2, pp. 241-242, 2011.

[12] JW Creswell, Research design qualitative \& quantitative approaches. Jakarta: sage Publications, Inc., 1994.

[13] Christophe, Joigneauxa, Elsie Rockwellb, "Cause or consequence? Framing and keying mediation in a French secondary classroom," Learning, Culture and Social Interaction, vol. 24, p. 3, 2020.

[14] M. Usman, "Development of the German Vocabulary Learning Model (WORTSCHATZ) Based on the SMCRBERLO Communication Model in State High Schools in Makassar City," Eralingua J. Educator. Bhs. Foreign and Literature, vol. 2, no. 1, p. 17, 2018.

[15] D. Mulyana, Ilmu Komunikasi Suatu Pengantar, 10th Bandung: PT.Remaja Rosdakarya, 2007. 